\title{
Analysis of Graphite Nuclear in Spheroidal Graphite Cast Iron and Mechanism of Nodule Count Increase by Bismuth Oxide*1
}

\author{
Hiroaki Tsuji ${ }^{1, * 2}$, Hiroyuki Chono ${ }^{1}$, Nobuya Yamamoto ${ }^{1}$, Tokio $\mathrm{Kai}^{1}$ and Yoshio Igarashi ${ }^{2}$ \\ ${ }^{1}$ TOYO DENKA KOGYO CO., LTD., Kochi 781-9525, Japan \\ ${ }^{2}$ Micro Analysis Center, Shimotsuke 329-0434, Japan
}

In order to elucidate the mechanism of nodule count increase by $\mathrm{Bi}$, we analyzed spheroidal graphite cast iron with increased nodule count by Bi addition. In the Scanning Electron Microscope - Energy Dispersive X-ray Spectrometry (SEM-EDS) analysis, Bi was identified to be present near the center of the spheroidal graphite. The center of this spherical graphite was pretreated by Focused Ion Beam (FIB) micro sampling method to prepare analytical sample and analyzed by Transmission Electron Microscope - Energy Dispersive X-ray Spectrometry (TEM-EDS). As a result, it was found that $\mathrm{Bi}$ exists as $\mathrm{Bi}-\mathrm{La}-\mathrm{Ce}-\mathrm{Sb}$ oxide on the outer periphery of the graphite core centered on (MgCa) $\mathrm{S}$.

To verify the effect of the $\mathrm{Bi}-\mathrm{La}-\mathrm{Ce}-\mathrm{Sb}$ oxide on the increase in nodule count, we first used mechanical alloying to prototype a Bi-La-Ce$\mathrm{Sb}$ oxide having the same composition as that observed via TEM-EDS. This oxide was then added to the molten spheroidal graphite cast iron. As a result, nodule count did not increase with the addition of the prototype $\mathrm{Bi}-\mathrm{La}-\mathrm{Ce}-\mathrm{Sb}$ oxide alone, but when the prototype $\mathrm{Bi}-\mathrm{La}-\mathrm{Ce}-\mathrm{Sb}$ oxide and $\mathrm{Fe}-\mathrm{Si}$ inoculants were mixed and added, the nodule count increased more than when only the Fe-Si inoculants was added.

From these results, it is considered that the effect of increasing nodule count by Bi addition is that Bi acts on graphite nucleus as an oxide. [doi:10.2320/matertrans.F-M2021836]

(Received April 16, 2021; Accepted June 4, 2021; Published August 25, 2021)

Keywords: spheroidal graphite cast iron, bismuth, graphite nucleus, oxide, nodule count

\section{Introduction}

In spheroidal graphite cast iron, increasing the nodule count provides material strengthening ${ }^{1,2)}$ and defect reduction by suppressing chill, shrinkage, and chunky graphite. ${ }^{3-5)}$ As a method of increasing nodule count, inoculation treatment is generally performed in the production of spheroidal graphite cast iron. ${ }^{6,7)}$ Various inoculants are used in the inoculation process, and most of them are based on $\mathrm{Fe}-\mathrm{Si}$ alloys made by alloying $\mathrm{Al}, \mathrm{Ca}, \mathrm{Sr}, \mathrm{Ba}, \mathrm{Ce}, \mathrm{La}, \mathrm{Zr}, \mathrm{Bi}$, etc. ${ }^{6-8)}$ In particular, although $\mathrm{Bi}$ is considered to be a spheroidizing inhibitor, ${ }^{9,10)}$ it can also significantly increase nodule count. ${ }^{11,12)}$ According to the study conducted by Horie et al., ${ }^{13,14)}$ the addition of a small amount of $\mathrm{Bi}$ significantly increases the nodule count, and the addition of $\mathrm{Bi}_{2} \mathrm{O}_{3}$ and $\mathrm{Bi}_{2} \mathrm{~S}_{3}$ has the same effect. In this study, the graphite sample containing $\mathrm{Bi}$ was analyzed by energy dispersive spectroscopy (EDS), and Bi was detected in the center of the graphite.

From these research reports, the effect of $\mathrm{Bi}$ in increasing the nodule count is clear; however, the related mechanism and the form of $\mathrm{Bi}$ present in graphite have not been clarified yet. Therefore, in this study, to determine the mechanism by which the use of Bi increases the nodule count in spheroidal graphite cast iron, Bi was added to spheroidal graphite, and the internal structure of the graphite was then observed. This was performed using Igarashi's advanced electron microscopy method, ${ }^{15,16)}$ and the crystallized graphite nucleus was then analyzed. The analysis results showed that $\mathrm{Bi}$ could be observed in the $\mathrm{Bi}, \mathrm{La}, \mathrm{Ce}$, and $\mathrm{Sb}$ oxides on the outer circumference of the graphite nucleus. Additionally, the observed oxides were produced and directly added to the molten metal to verify their effect on increasing the nodule count.

\footnotetext{
${ }^{* 1}$ This Paper was Originally Published in Japanese in J. JFS 91 (2019) 221227. Some spelling errors were modified.

${ }^{* 2}$ Corresponding author, E-mail: h-tsuji@toyodenka.co.jp
}

\section{Observation and Analysis of Graphite Nucleus}

\subsection{Preparation of graphite nucleus observation sample} Samples for observing the graphite nuclei were prepared under the following conditions. The molten metal of cast iron with a eutectic composition was spheroidized with an $\mathrm{Fe}-\mathrm{Si}-$ $\mathrm{Mg}-\mathrm{Ca}-\mathrm{RE}$ alloy, with and without addition of the $\mathrm{Fe}-\mathrm{Si}-\mathrm{Bi}$ alloy. A t 25-mm Y block and a mushroom-shaped mold were used for the optical emission spectrometer. To confirm the phenomenon of increase in the nodule count due to $\mathrm{Bi}$, the nodule count in the $\mathrm{t} 25 \mathrm{-mm}$ Y block was measured. The microstructures are shown in Fig. 1. The t 25-mm Y block sample with and without Fe-Si-Bi alloy had 436 and 172 graphite grains $/ \mathrm{mm}^{2}$, respectively. Thus, the increase in the nodule count due to the addition of Bi alloy was confirmed.

The mushroom-shaped mold was used for composition analysis by an optical emission spectrometer and for scanning electron microscope (SEM)/transmission electron microscope (TEM) observations. The material cast in the quenching mold was used for SEM/TEM observations such as to facilitate the observation of the nuclear material of the graphite nucleus. This is because the molten metal is rapidly cooled and solidified at the micrographite stage in the early stages of graphite formation. Table 1 shows the compositions after the addition of the Fe-Si-Bi alloy. Bi was not detected in the optical emission spectrometer in the molten metal before the addition of the $\mathrm{Fe}-\mathrm{Si}-\mathrm{Bi}$ alloy; however, the concentration of $\mathrm{Bi}$ in the molten metal was $22 \mathrm{ppm}$ after the addition of the $\mathrm{Fe}-\mathrm{Si}-\mathrm{Bi}$ alloy, confirming that the prepared sample contained $\mathrm{Bi}$.

\subsection{SEM-EDS observation of graphite nucleus}

Next, to observe the graphite nucleus of the sample by SEM and TEM, the sample was prepared as shown in Fig. 2. Figure 3 shows the SEM and EDS analysis results of the nuclear material of spheroidal graphite. Characteristic X-ray peaks of $\mathrm{Bi}, \mathrm{Mg}, \mathrm{Si}, \mathrm{S}$, and $\mathrm{La}$ can be observed in the white 


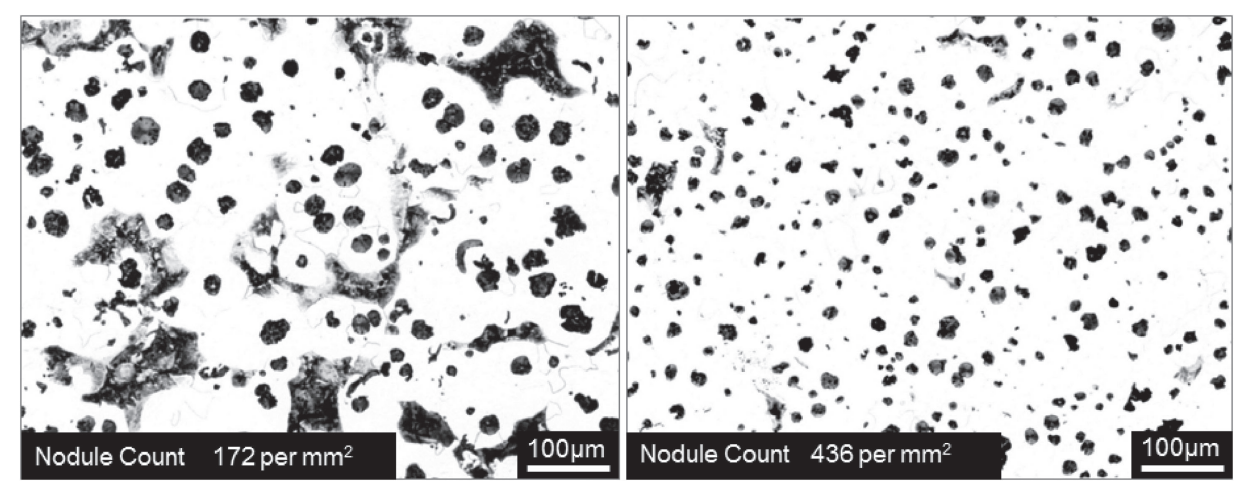

Fig. 1 Microstructure of $25 \mathrm{~mm}$ thickness $\mathrm{Y}$ block.

Table 1 Chemical composition of molten metals.

\begin{tabular}{l|cccccc}
\multicolumn{1}{l|}{} & $\mathrm{C}$ & $\mathrm{Si}$ & $\mathrm{Mn}$ & $\mathrm{P}$ & $\mathrm{S}$ & $\mathrm{Mg}$ \\
\hline No addition & 3.6 & 2.12 & 0.21 & 0.01 & 0.010 & 0.035 \\
Bi addition & 3.6 & 2.75 & 0.30 & 0.02 & 0.010 & 0.052 \\
\hline \multicolumn{1}{l}{} & & & \multicolumn{4}{c}{ mass ppm } \\
\hline No addition & $\mathrm{Ca}$ & $\mathrm{Sb}$ & $\mathrm{La}$ & $\mathrm{Ce}$ & $\mathrm{Bi}$ & \\
Bi addition & 23 & 37 & 48 & 88 & - & \\
\hline & 20 & 57 & 55 & 95 & 22 &
\end{tabular}

\begin{tabular}{|c|}
\hline Cut off small TP by wet \\
\hline$\downarrow$ \\
\hline $\begin{array}{l}\text { Wet polish with SiC abrasive paper } \\
(\# 240 \rightarrow \# 600 \rightarrow \# 1000 \rightarrow \# 1500)\end{array}$ \\
\hline$\downarrow$ \\
\hline $\begin{array}{l}\text { Intermediate polish with diamond past } \\
\qquad(9 \mu \mathrm{m} \rightarrow 6 \mu \mathrm{m})\end{array}$ \\
\hline 1 \\
\hline $\begin{array}{l}\text { Intermediate polish with diamond past } \\
\qquad(3 \mu \mathrm{m} \rightarrow 1 \mu \mathrm{m})\end{array}$ \\
\hline$t$ \\
\hline Super-sonic cleaning in aceton \\
\hline$\downarrow$ \\
\hline $\begin{array}{l}\text { Cleaning of polished surface } \\
\text { (Soft polish with paper wetted with aceton) }\end{array}$ \\
\hline 7 \\
\hline Examination analysis by SEM-EDS \\
\hline$\downarrow$ \\
\hline $\begin{array}{c}\text { FIB micro sampling } \\
(\text { W } 25 \mu \mathrm{m} \times \mathrm{H} 20 \mu \mathrm{m} \times \mathrm{t}<100 \mathrm{~nm} \text { ) }\end{array}$ \\
\hline$\downarrow$ \\
\hline Examination analysis by TEM-EDS \\
\hline
\end{tabular}

Fig. 2 Procedure of preparation of specimen for observing graphite.

part in the reflected electron image of the central part of graphite, which seems to be the graphite nucleus. From this result, it is considered that the added $\mathrm{Bi}$ exists near the graphite nucleus. The structure of the graphite nucleus is not

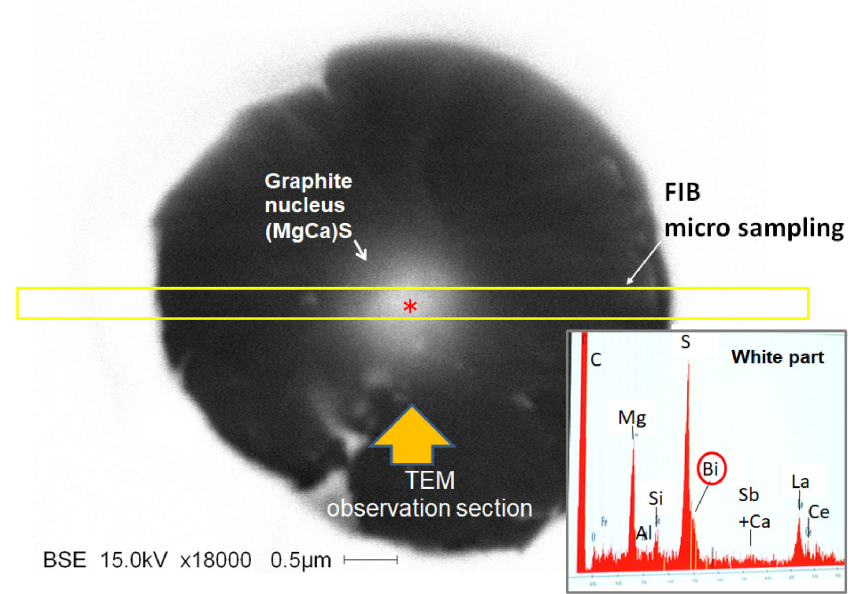

Fig. 3 Observation and analysis of graphite nucleus by SEM-EDS.

clear because the graphite nucleus is buried in graphite on the sample surface, as observed by SEM-EDS. To clarify the morphology in which Bi exists, the part analyzed by SEMEDS was analyzed by TEM-EDS. As shown in Fig. 2, the sample was prepared by processing the sample observation site after SEM-EDS analysis into thin sections using the focused ion beam microsampling method.

\subsection{Microstructure analysis of nuclear material by TEM}

Figure 4 shows the results of the mapping analysis by TEM-EDS at the points where the characteristic X-ray peak of $\mathrm{Bi}$ was confirmed by SEM-EDS analysis. The graphite core had a diameter of approximately $1-2 \mu \mathrm{m}$ and a roughly spherical shape. The compositions of the graphite core were $(\mathrm{MgCa}) \mathrm{S}$ in the center, $(\mathrm{LaCe}) \mathrm{S}$ in the surface layer, and (BiRESb) $\mathrm{O}$ and $\mathrm{MgOS}$. Figure 5 shows a composition distribution map of the graphite nucleus traced from the information obtained by the mapping analysis.

Similarly, when another graphite was subjected to TEMEDS analysis, a graphite nucleus consisting of (BiRESb) O containing $\mathrm{Bi}$ was observed in the surface layer centered on $(\mathrm{MgCa}) \mathrm{S}$, as in the previous analysis results. Figure 6 shows the results of the mapping analysis, and Fig. 7 shows the composition distribution map of the graphite nucleus traced from the information obtained by the mapping analysis.

Table 2 shows the results of the TEM-EDS analysis of the phase containing $\mathrm{Bi}$. The Bi-containing phase observed in the graphite nucleus had a composition of $45.6 \%$ of $\mathrm{Bi}_{2} \mathrm{O}_{3}$, 

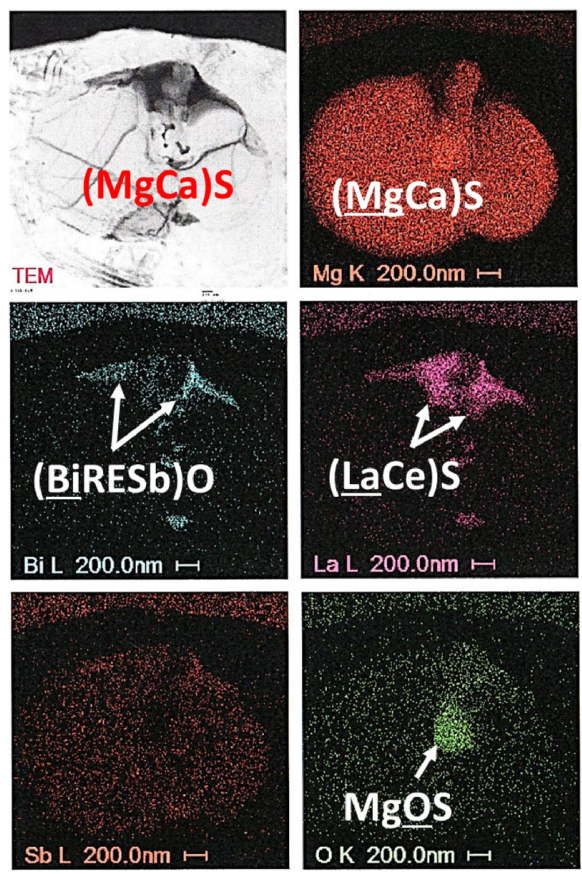

Fig. 4 Mapping analysis results of graphite nucleus by TEM-EDS (1).
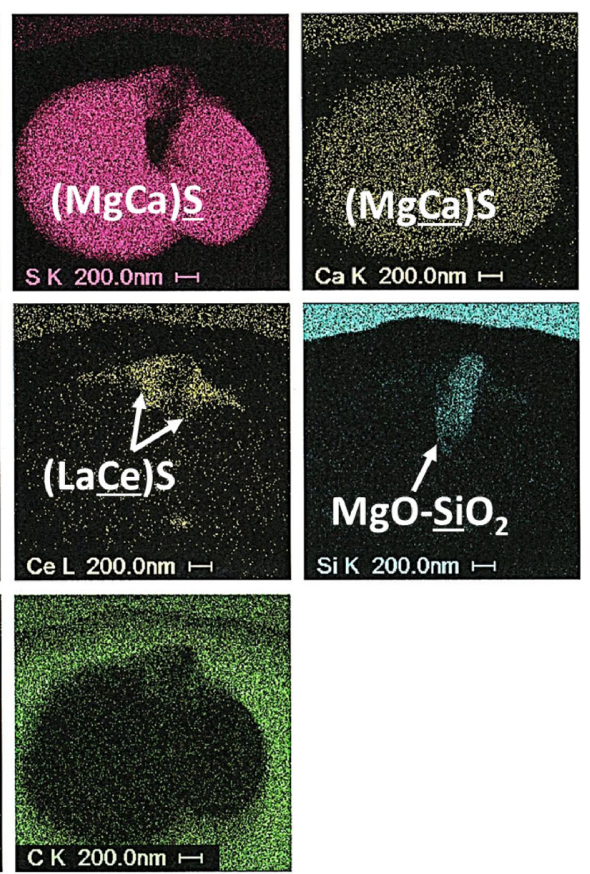

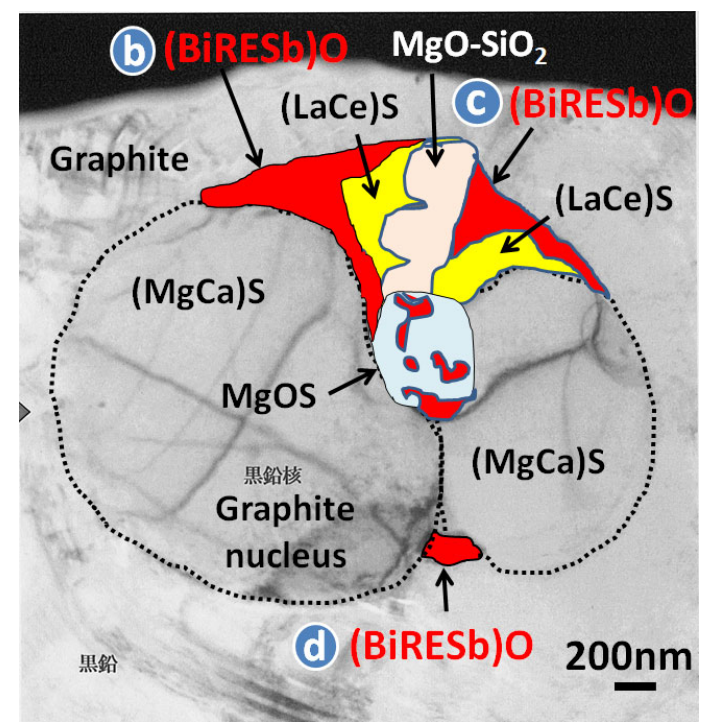

Fig. 5 Composition distribution chart of graphite nucleus (1).

$38.7 \%$ of $\mathrm{La}_{2} \mathrm{O}_{3}, 10.7 \%$ of $\mathrm{CeO}_{2}$, and $5.0 \%$ of $\mathrm{Sb}_{2} \mathrm{O}_{3}$ as measured by four points.

From these results, it is considered that $\mathrm{Bi}$ increases the nodule count because the $\mathrm{Bi}$ added to the molten metal becomes an oxide containing $\mathrm{Bi}$ and $\mathrm{La}, \mathrm{Ce}$, and $\mathrm{Sb}$, and this oxide acts on the graphite nucleus. Next, a Bi-La-Ce-Sb oxide with the same composition as the result analyzed by this TEM-EDS analysis was produced, and an experiment was conducted to determine whether the nodule count increased by adding it directly to the molten metal.

\section{Trial Production of Bi-La-Ce-Sb Oxide}

The oxide to be produced should have the same composition as that obtained by TEM-EDS quantitative analysis and the particle size should be as small as possible, equivalent to that of the graphite nucleus, as it is assumed to act on the graphite nucleus. A Bi-La-Ce-Sb oxide was produced according to the procedure shown in Fig. 8 to meet this condition. $\mathrm{Bi}_{2} \mathrm{O}_{3}, \mathrm{La}_{2} \mathrm{O}_{3}, \mathrm{CeO}_{2}$, and $\mathrm{Sb}_{2} \mathrm{O}_{3}$ were used as raw materials with a purity of more than $99 \%$ and a particle size of less than $200 \mathrm{~nm}$, and were weighed and mixed to obtain the composition shown in Table 2. The mixture was placed in an alumina pot containing zirconia balls to obtain a uniform composition, and crushed and mixed with a planetary ball mill at a rotation speed of $260 \mathrm{rpm}$ for $5 \mathrm{~h}$.

The analysis was performed via SEM-EDS and X-ray diffraction (XRD) to confirm the mixed state of the prototype sample. Figure 9 shows the analysis results of SEM-EDS. Before crushing and mixing, each oxide was segregated. However, after crushing and mixing, it was observed that each oxide was uniformly dispersed and mixed.

The XRD analysis results are shown in Fig. 10. The diffraction intensities of $\mathrm{Bi}_{2} \mathrm{O}_{3}, \mathrm{La}_{2} \mathrm{O}_{3}, \mathrm{CeO}_{2}$, and $\mathrm{Sb}_{2} \mathrm{O}_{3}$ are smaller and broader than those of the raw materials before the crushing and mixing treatment. This indicates that the crystal size of the prototype oxide is small. From this analysis result, it is considered that the prototype oxide is equivalent to the oxide observed in the TEM-EDS analysis, thus, a direct addition experiment to the molten metal was conducted.

\section{Experimental Method and Results}

\subsection{Bi-La-Ce-Sb oxide addition method}

The $\mathrm{Bi}-\mathrm{La}-\mathrm{Ce}-\mathrm{Sb}$ oxide prepared by crushing and mixing was directly added to the molten spheroidal graphite cast iron under various conditions, and the effect of the oxide on the increasing nodule count was verified. The oxide addition conditions were the two conditions shown in Table 3 .

In condition 1, four levels of oxide addition rate were set. The RE addition rate in the graphite spheroidization 

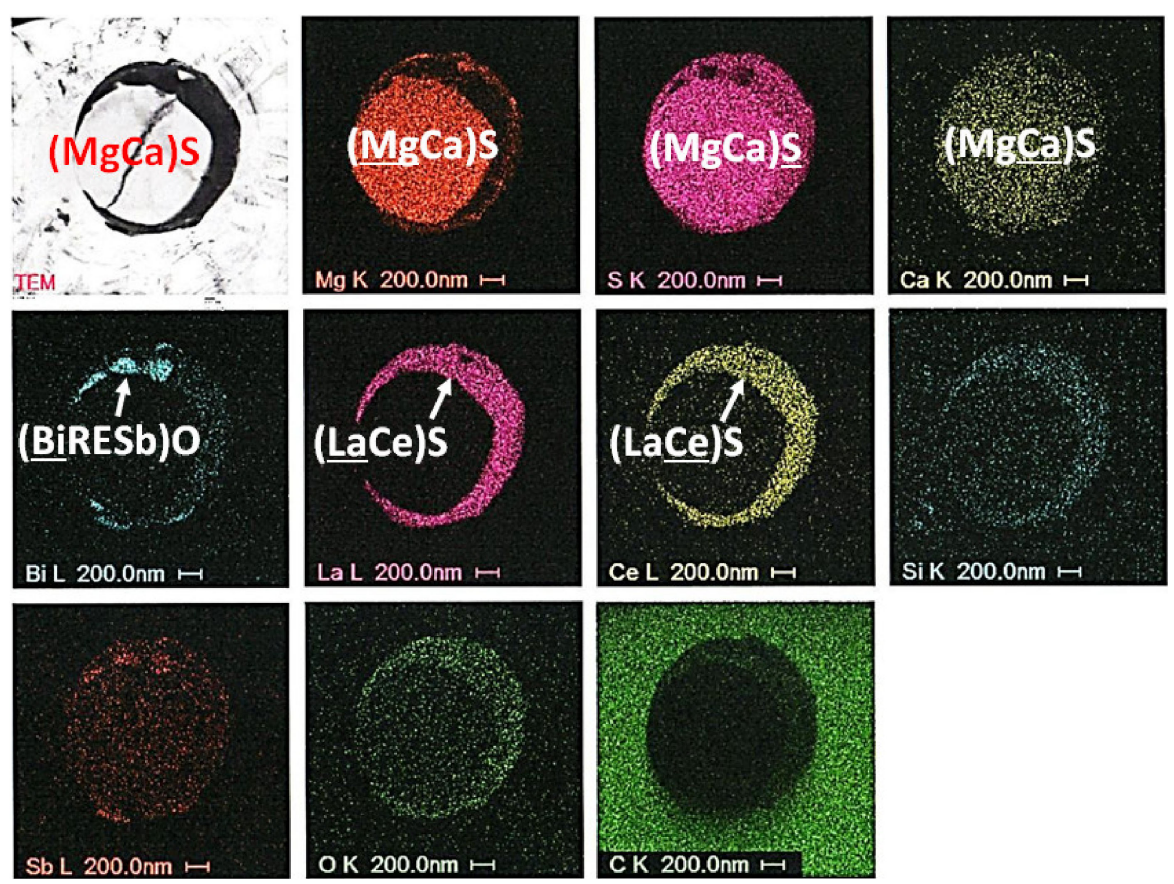

Fig. 6 Mapping analysis results of graphite nucleus by TEM-EDS (2).

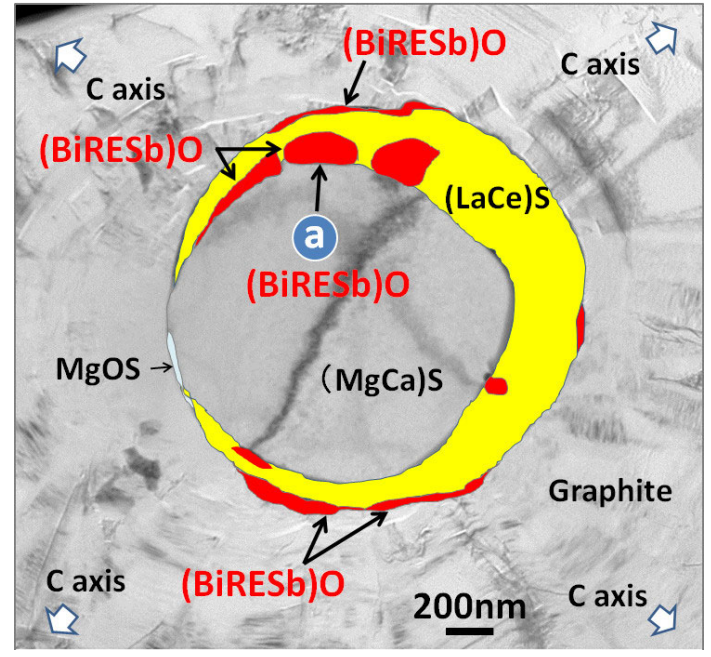

Fig. 7 Composition distribution chart of graphite nucleus (2).
Table 2 Quantitative analysis result of Bi containing phases by TEM-EDS

\begin{tabular}{rrrrr} 
& & & & mass \% \\
\hline & $\mathrm{Bi}_{2} \mathrm{O}_{3}$ & $\mathrm{La}_{2} \mathrm{O}_{3}$ & $\mathrm{CeO}_{2}$ & $\mathrm{Sb}_{2} \mathrm{O}_{3}$ \\
\hline $\mathrm{a}$ & 47.3 & 35.6 & 14.1 & 3.0 \\
$\mathrm{~b}$ & 48.2 & 35.5 & 11.4 & 4.9 \\
$\mathrm{c}$ & 41.6 & 42.9 & 9.0 & 6.5 \\
d & 45.4 & 40.7 & 8.4 & 5.5 \\
\hline $\mathrm{AVG}$ & 45.6 & 38.7 & 10.7 & 5.0 \\
\hline
\end{tabular}

treatment was also included in the experimental level to separately evaluate the effect of $\mathrm{La}_{2} \mathrm{O}_{3}$ and $\mathrm{CeO}$ contained in the prototype oxide and the effect of $\mathrm{Ce}$ and $\mathrm{La}$ added to the graphite spheroidization treatment.

Condition 2 corresponded to a mixed addition of $\mathrm{Bi}-\mathrm{La}-$ $\mathrm{Ce}-\mathrm{Sb}$ oxide and inoculants, because it is difficult for the oxide alone to invade the molten metal. ${ }^{17)}$ In addition, the

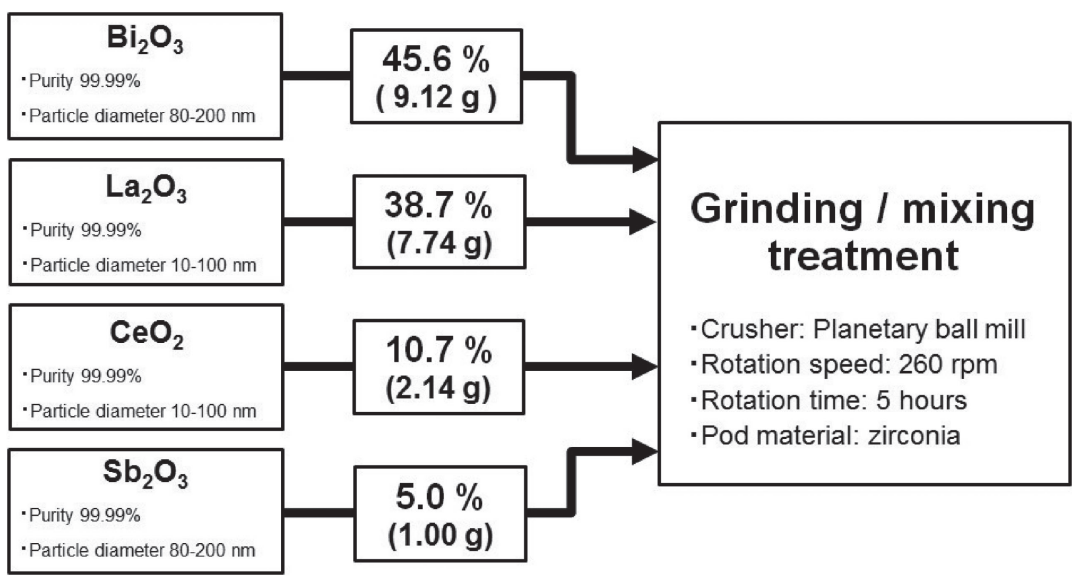

Fig. 8 Production condition of $\mathrm{Bi}-\mathrm{La}-\mathrm{Ce}-\mathrm{Sb}$ oxide. 

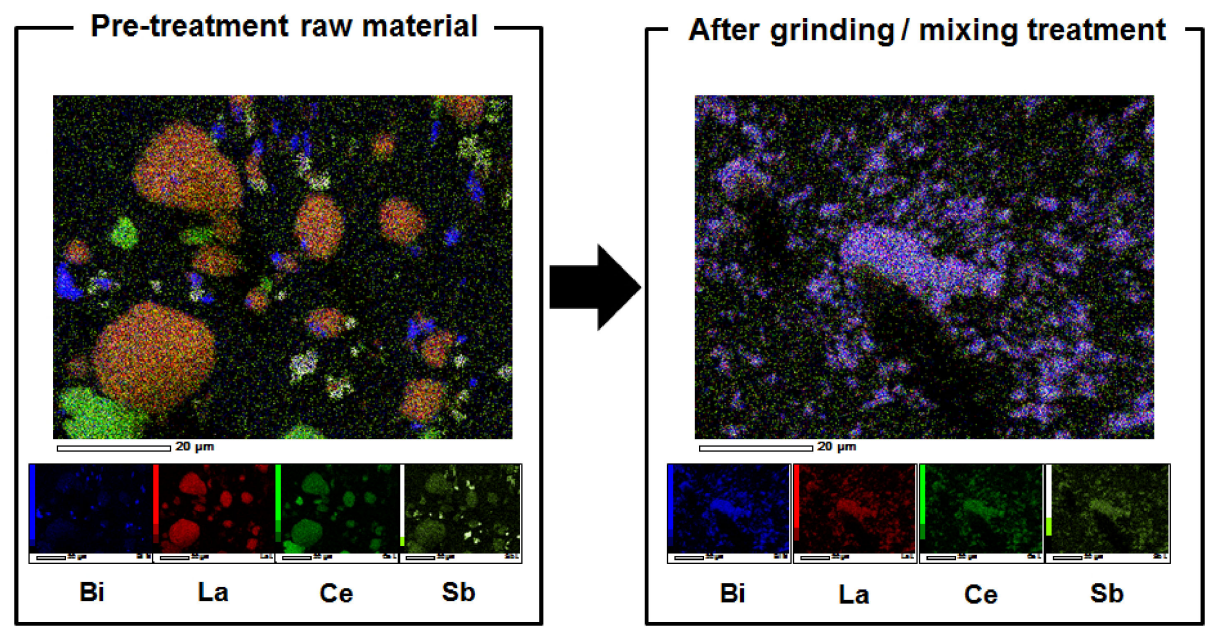

Fig. 9 EDS analysis results of prototyped $\mathrm{Bi}-\mathrm{La}-\mathrm{Ce}-\mathrm{Sb}$ oxide.

Pre-treatment raw material

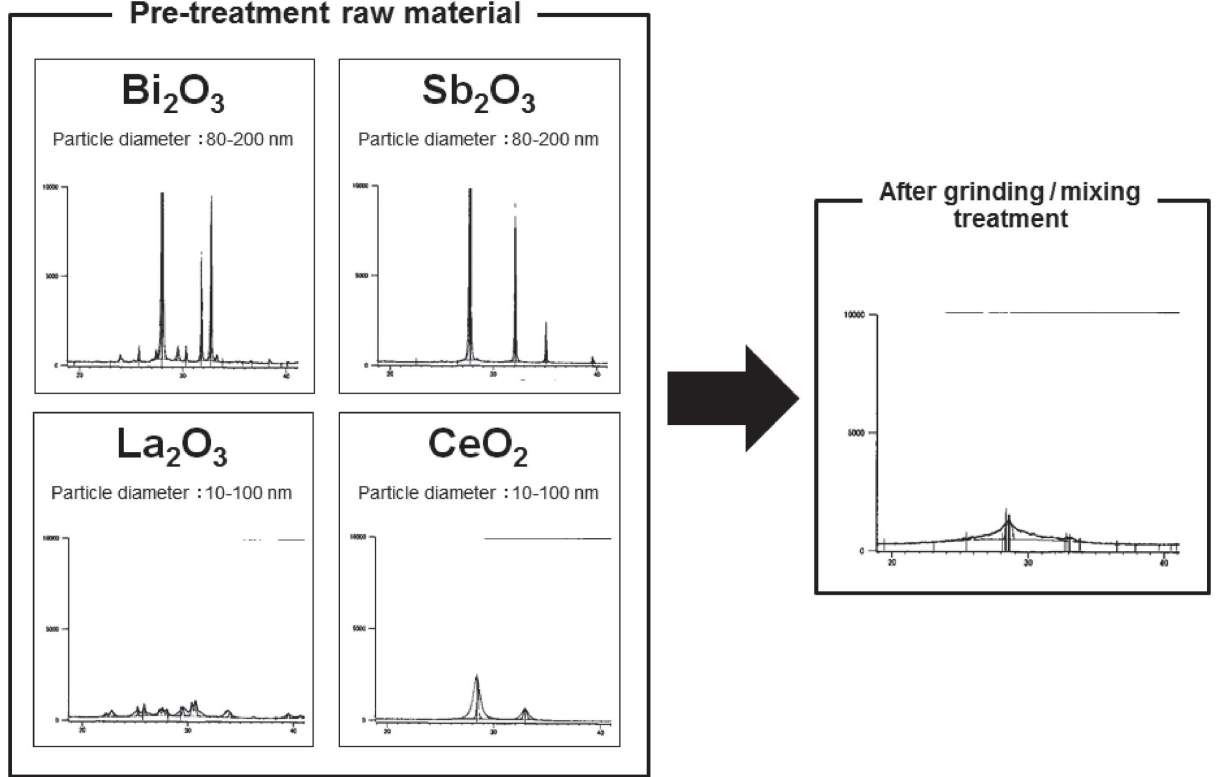

Fig. 10 X-ray diffraction results of prototyped $\mathrm{Bi}-\mathrm{La}-\mathrm{Ce}-\mathrm{Sb}$ oxide.

Table 3 Bi-La-Ce-Sb oxide addition conditions.

\begin{tabular}{|c|l|c|}
\hline \multirow{2}{*}{$\begin{array}{c}\text { Condition } \\
1\end{array}$} & $\begin{array}{l}\text { RE addition rate in } \\
\text { graphite spheroidization } \\
\text { treatment (mass\%) }\end{array}$ & $<0.001,0.023$ \\
\cline { 2 - 3 } & $\begin{array}{l}\mathrm{Bi} \cdot \mathrm{Sb} \cdot \mathrm{La} \cdot \mathrm{Ce} \text { oxide } \\
\text { addition rate (\%) }\end{array}$ & $0,0.01,0.05,0.1$ \\
\hline \multirow{4}{*}{$\begin{array}{c}\text { Condition } \\
2\end{array}$} & $\begin{array}{l}\mathrm{RE} \text { addition rate in } \\
\text { graphite spheroidization } \\
\text { treatment (mass\%) }\end{array}$ & $<0.001,0.023$ \\
\cline { 2 - 3 } & Inoculant type & $\begin{array}{l}\mathrm{Fe}-\mathrm{Si} \text {-Ba , Fe-Si-RE } \\
\mathrm{Fe}-\mathrm{Sl}-\mathrm{Zr}, \text { non }\end{array}$ \\
\cline { 2 - 3 } & $\begin{array}{l}\mathrm{Bi} \cdot \mathrm{Sb} \cdot \mathrm{La} \cdot \mathrm{Ce} \text { oxide } \\
\text { addition rate (\%) }\end{array}$ & $\mathbf{0 , 0 . 0 1}$ \\
\hline
\end{tabular}

oxide may aggregate, float, and separate, which can hinder its action on the molten metal. The types of inoculants mixed with oxides were set to four levels, including those not mixed with inoculants, and the oxide addition rate was set to two levels. The RE addition rate of the graphite spheroidization treatment was included as a factor for the same reason as in condition 1 .
Table 4 Spheronizing agents and inoculant composition.

\begin{tabular}{l|c|c|c|c}
\multicolumn{1}{c}{} & \multicolumn{3}{r}{ mass \% } \\
\hline Spheronizing agent & Si & Mg & Ca & RE \\
\hline Fe-Si-Mg-Ca-RE & 45 & 4.7 & 2.5 & 1.9 \\
Fe-Si-Mg-Ca & 44 & 4.8 & 2.1 & $<0.05$ \\
\hline
\end{tabular}

\begin{tabular}{l|c|c|c}
\multicolumn{4}{|c}{ mass $\%$} \\
\hline Inoculant & $\mathrm{Si}$ & $\mathrm{Ca}$ & $\mathrm{Al}$ \\
\hline Fe-Si-Al & 74 & 0.8 & 1.2 \\
\hline
\end{tabular}

Next, the procedure for adding $\mathrm{Bi}-\mathrm{La}-\mathrm{Ce}-\mathrm{Sb}$ oxide is described. The base molten metal was dissolved by adding $50 \%$ of crude iron and $46 \%$ of iron scrap, and the remaining $4 \%$ were adjusted by adding electrode scrap, $\mathrm{Fe}-\mathrm{Si}$, and $\mathrm{Fe}-$ $\mathrm{S}$. This molten metal was subjected to graphite spheroidization treatment using spheroidizing agents and ladle inoculants, as shown in Table 4, using the sandwich method. As shown in Fig. 11, the oxide was added to the molten metal by placing $\mathrm{Bi}-\mathrm{La}-\mathrm{Ce}-\mathrm{Sb}$ oxide in a shell cup with a diameter of $30 \mathrm{~mm}$ and a height of $50 \mathrm{~mm}$, and the molten metal was 


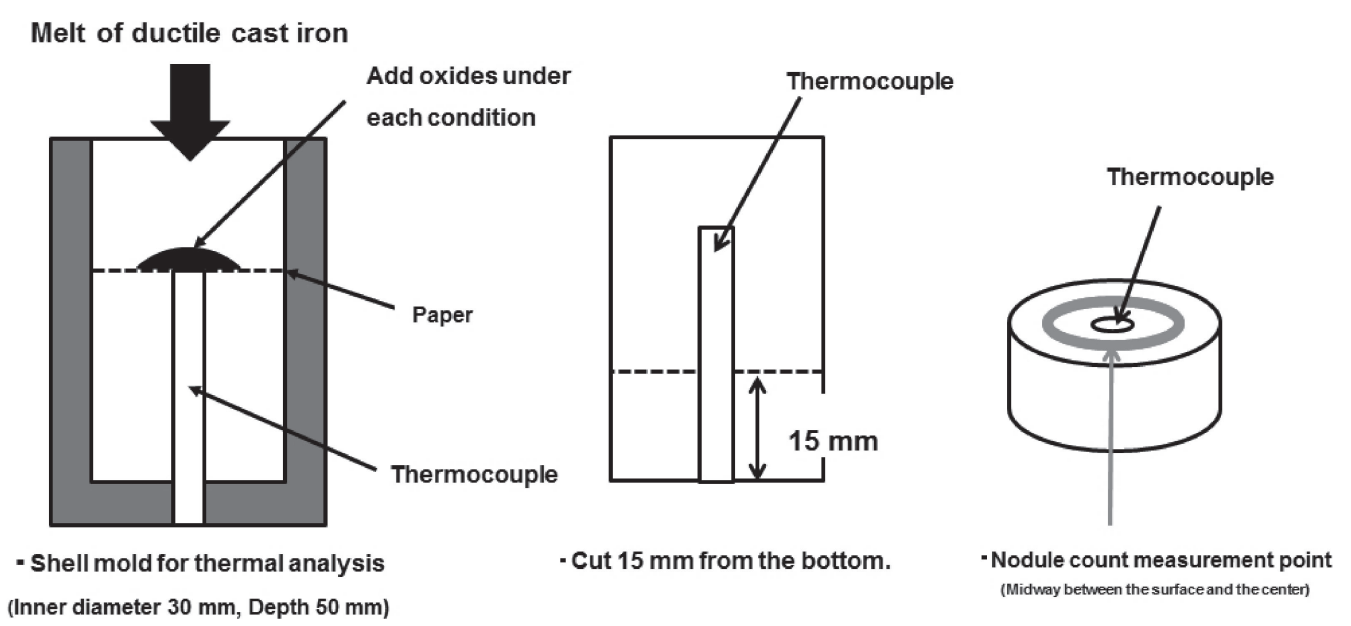

Fig. 11 Method of adding $\mathrm{Bi}-\mathrm{La}-\mathrm{Ce}-\mathrm{Sb}$ oxide and nodule count measurement place.

Table 5 Inoculants composition mixed with oxide.

\begin{tabular}{lcccccc} 
& \multicolumn{1}{c}{ mass \% } \\
\hline Inoculant & $\mathrm{Si}$ & $\mathrm{Ca}$ & $\mathrm{Al}$ & $\mathrm{Ba}$ & $\mathrm{RE}$ & $\mathrm{Zr}$ \\
\hline Fe-Si-Ba & 72 & 1.3 & 1.8 & 0.8 & - & - \\
Fe-Si-RE & 72 & 1.6 & 0.9 & - & 3.9 & - \\
Fe-Si-Zr & 70 & 2.3 & 1.2 & - & - & 1.6 \\
\hline
\end{tabular}

poured into it. Under the condition that the oxide and the inoculants (particle size $<0.25 \mathrm{~mm}$ ) were mixed and added, the inoculants of the compositions in Table 5 were used, and the addition rate of the inoculants was $0.1 \%$. As shown in Fig. 11, the nodule count measurement point was cut $15 \mathrm{~mm}$ from the bottom of the sample to create five fields of view between the central and outer peripheral surfaces. The nodule count was measured by image analysis, and graphite with a diameter of less than $5 \mu \mathrm{m}$ was excluded.

\subsection{Bi-La-Ce-Sb oxide addition experimental results}

Figure 12 shows the results for condition 1 . When only $\mathrm{Bi}-\mathrm{La}-\mathrm{Ce}-\mathrm{Sb}$ oxide was added, the nodule count did not increase regardless of the $\mathrm{RE}$ addition rate or the oxide addition rate.

Figure 13 shows the results when the $\mathrm{Bi}-\mathrm{La}-\mathrm{Ce}-\mathrm{Sb}$ oxide under condition 2 and the inoculants were mixed and added. When $\mathrm{Bi}-\mathrm{La}-\mathrm{Ce}-\mathrm{Sb}$ oxide and an inoculant were mixed and added, the nodule count increased compared to the case

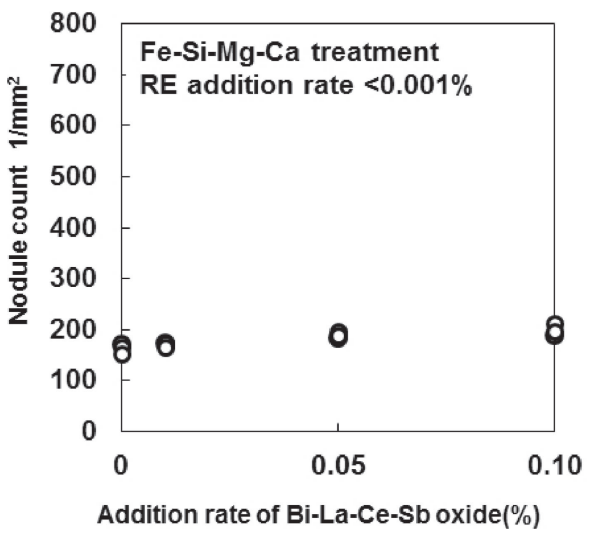

when only the inoculum was added, regardless of the RE addition rate and the type of inoculant to be mixed. Figure 14 shows the microstructure of the sample with the largest increase in nodule count in this test. The higher nodule count was obtained under the conditions of $\mathrm{Fe}-\mathrm{Si}-\mathrm{Mg}-\mathrm{Ca}-\mathrm{RE}$ alloy treatment and mixed addition of $\mathrm{Bi}-\mathrm{La}-\mathrm{Ce}-\mathrm{Sb}$ oxide and $\mathrm{Fe}-\mathrm{Si}-\mathrm{Zr}$ inoculants.

\section{Consideration}

\subsection{Analysis results of graphite nucleus of Bi-added spheroidal graphite cast iron}

In the observation of graphite nuclei by SEM/TEM, Bi added to the spheroidal graphite cast iron molten metal was observed as a composite oxide of $\mathrm{Bi}_{2} \mathrm{O}_{3}-\mathrm{La}_{2} \mathrm{O}_{3}-\mathrm{CeO}_{2}-\mathrm{Sb}_{2} \mathrm{O}_{3}$ to cover the graphite nucleus. Thus, it is considered that the observed oxide was a liquid in the molten metal. Bi added to the molten metal became $\mathrm{Bi}_{2} \mathrm{O}_{3}$, mixed with other oxides such as $\mathrm{La}_{2} \mathrm{O}_{3}, \mathrm{CeO}_{2}$, and $\mathrm{Sb}_{2} \mathrm{O}_{3}$, and spherically covered the graphite nucleus as a liquid phase mainly composed of $(\mathrm{MgCa}) \mathrm{S}$. Therefore, it is considered to effectively act as a nucleus of spheroidal graphite.

\subsection{Effect of the direct addition of Bi-La-Ce-Sb oxide}

The oxide with the same composition as the composite oxide of $\mathrm{Bi}_{2} \mathrm{O}_{3}-\mathrm{La}_{2} \mathrm{O}_{3}-\mathrm{CeO}_{2}-\mathrm{Sb}_{2} \mathrm{O}_{3}$ obtained by TEM-EDS measurement was produced and directly added to the molten

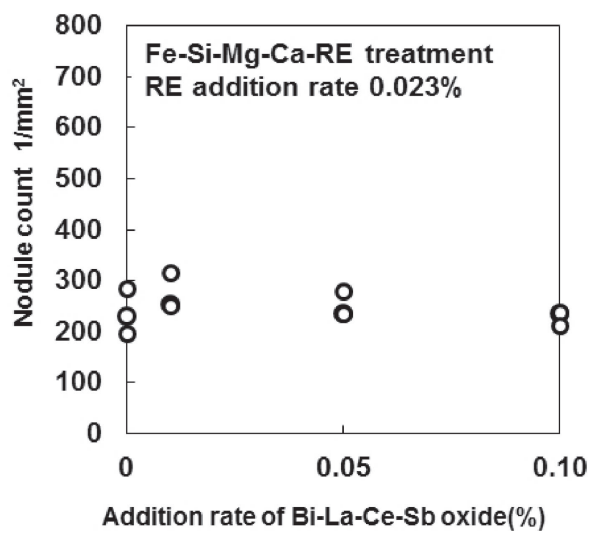

Fig. 12 Relationship between the addition rate of $\mathrm{Bi}-\mathrm{La}-\mathrm{Ce}-\mathrm{Sb}$ oxide and nodule count. 

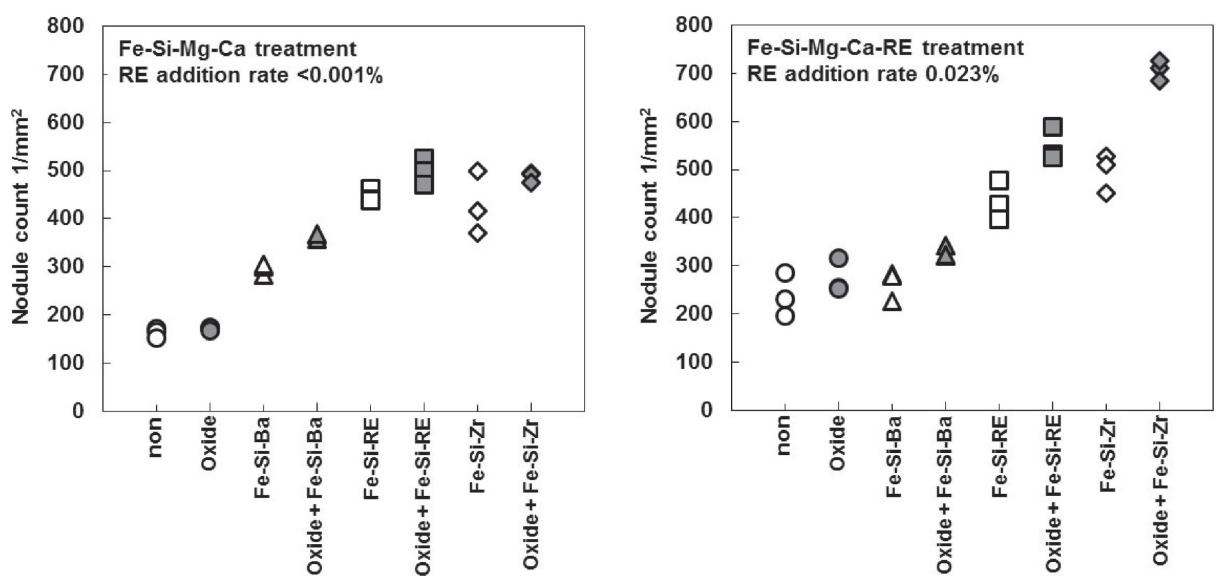

Fig. 13 Increase effect of nodule count by mixing $\mathrm{Bi}-\mathrm{La}-\mathrm{Ce}-\mathrm{Sb}$ oxide and inoculants.

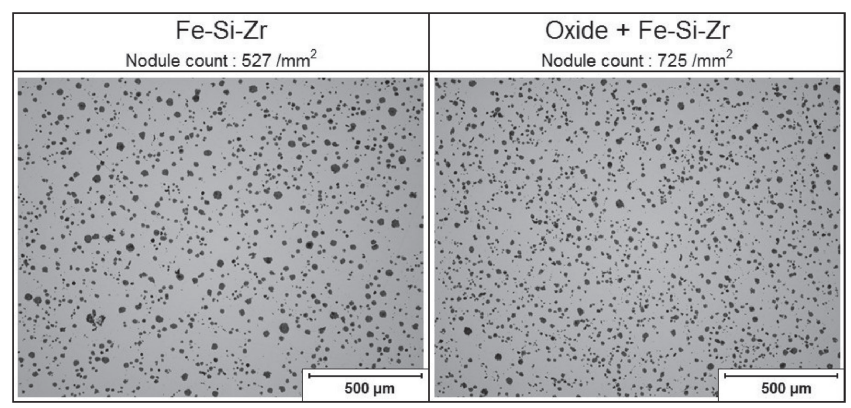

Fig. 14 Microstructure of sample mixed with $\mathrm{Bi}-\mathrm{La}-\mathrm{Ce}-\mathrm{Sb}$ oxide and $\mathrm{Fe}-$ $\mathrm{Si}-\mathrm{Zr}$ inoculants.

spheroidal graphite cast iron. The nodule count did not increase regardless of the addition rate, but when the oxide and the inoculants were mixed and added, the nodule count increased compared to the case when only the inoculants were added. It is considered that the nodule count does not increase with the addition of $\mathrm{Bi}-\mathrm{La}-\mathrm{Ce}-\mathrm{Sb}$ oxide alone, as it does not invade the molten metal. This is because the oxide is nano-sized and has low wettability to the molten metal. ${ }^{17}$ ) This result is considered to be a problem due to the method of adding the oxide to the molten metal.

In the case of mixed addition of $\mathrm{Bi}-\mathrm{La}-\mathrm{Ce}-\mathrm{Sb}$ oxide and inoculants, it is considered that the oxide invades the molten metal due to the diffusion of $\mathrm{Si}$ in the $\mathrm{Fe}-\mathrm{Si}$ inoculants, which are mixed and added with the oxide. In the study by Horie et al., ${ }^{13)}$ the addition of $\mathrm{Bi}_{2} \mathrm{O}_{3}$ and $\mathrm{Fe}-\mathrm{Si}-\mathrm{Mg}$ alloy increased the nodule count. It is considered that the oxide easily invaded the molten metal owing to the strong stirring of the molten metal by the reaction with $\mathrm{Mg}$. In addition, when $\mathrm{Si}$ in the Fe-Si inoculants was added to the molten metal, it caused an exothermic reaction and the ambient temperature increased, thus it was easier to dissolve the oxide added. As a result, it is considered that the $\mathrm{Bi}-\mathrm{La}-\mathrm{Ce}-\mathrm{Sb}$ oxide adheres to the outer periphery of the graphite nucleus and effectively acts as the nucleus for graphite crystallization.

Under the condition of mixed addition of $\mathrm{Bi}-\mathrm{La}-\mathrm{Ce}-\mathrm{Sb}$ oxide and inoculants, for all samples, regardless of the type of inoculant to be mixed and the RE addition rate during spheroidizing treatment, the nodule count increased when oxides were mixed and added. Therefore, it is considered that the $\mathrm{Bi}-\mathrm{La}-\mathrm{Ce}-\mathrm{Sb}$ oxide itself has the effect of increasing the nodule count.

\subsection{Effect of mixed addition of oxide and $\mathrm{Fe}-\mathrm{Si}-\mathrm{Zr}$ inoculants}

The higher increase of nodule count was obtained with the mixed addition of $\mathrm{Bi}-\mathrm{La}-\mathrm{Ce}-\mathrm{Sb}$ oxide and $\mathrm{Fe}-\mathrm{Si}-\mathrm{Zr}$ inoculants within the range of this experimental condition. According to Nakae's latest research, ${ }^{18)} \mathrm{Zr}$ refines dendrites; as a result, many regions where graphite crystallizes easily occur between austenites. Thus, $\mathrm{Zr}$ has the effect of increasing the nodule count. The results of this experiment are considered to be due to the synergistic effect of the dendrite miniaturization of $\mathrm{Zr}$ added from $\mathrm{Fe}-\mathrm{Si}-\mathrm{Zr}$ inoculants and the increase of the nodule count by the action of $\mathrm{Bi}-\mathrm{La}-\mathrm{Ce}-\mathrm{Sb}$ oxide on the graphite nucleus.

\section{Conclusion}

We analyzed the graphite nucleus after addition of $\mathrm{Bi}$, and conducted an experiment in which a produced $\mathrm{Bi}-\mathrm{La}-\mathrm{Ce}-\mathrm{Sb}$ oxide was directly added to the molten metal based on the analysis results. The results are summarized below.

(1) $\mathrm{Bi}$ was observed as a composite oxide of $\mathrm{Bi}_{2} \mathrm{O}_{3}, \mathrm{La}_{2} \mathrm{O}_{3}$, $\mathrm{CeO}_{2}$, and $\mathrm{Sb}_{2} \mathrm{O}_{3}$, covering the graphite nucleus mainly composed of $(\mathrm{MgCa}) \mathrm{S}$ in the analysis of Bi-added spheroidal graphite cast iron;

(2) Even if only $\mathrm{Bi}-\mathrm{La}-\mathrm{Ce}-\mathrm{Sb}$ oxide is directly added to the molten metal, the nodule count does not change. It is considered that the oxide does not invade the molten metal because the wettability between the oxide and the molten metal is low;

(3) The nodule count increased with the mixed addition of $\mathrm{Bi}-\mathrm{La}-\mathrm{Ce}-\mathrm{Sb}$ oxide and $\mathrm{Fe}-\mathrm{Si}$ inoculants.

It is considered that the oxides invade the molten metal due to the diffusion of $\mathrm{Si}$ when the $\mathrm{Si}$ in the $\mathrm{Fe}-\mathrm{Si}$ inoculants dissolves in the molten metal. In addition, the exothermic reaction when $\mathrm{Si}$ in the $\mathrm{Fe}-\mathrm{Si}$ inoculants is added to the molten metal raises the ambient temperature; at the same time, the added oxide becomes easier to dissolve, such that $\mathrm{Bi}-\mathrm{La}-\mathrm{Ce}-\mathrm{Sb}$ oxide adheres in a spherical shape and effectively acts on graphite crystallization; 
(4) The higher increase of nodule count was obtained under the mixed addition conditions of $\mathrm{Bi}-\mathrm{La}-\mathrm{Ce}-\mathrm{Sb}$ oxide and $\mathrm{Fe}-\mathrm{Si}-\mathrm{Zr}$ inoculants.

This effect of increasing the nodule count is considered to be due to the synergistic effect of the dendrite miniaturization by $\mathrm{Zr}$ added from $\mathrm{Fe}-\mathrm{Si}-\mathrm{Zr}$ inoculants and the $\mathrm{Bi}-\mathrm{La}-\mathrm{Ce}-\mathrm{Sb}$ oxide on the graphite nucleus.

\section{Acknowledgments}

We would like to thank Hideya Yamane, a researcher at the Casting Techology Research Lab. Hitachi Metals, Ltd. for his cooperation in the SEM and TEM measurements of graphite nuclei in this research.

\section{REFERENCES}

1) S. Harada, T. Kobayashi, T. Noguchi, H. Suzuki and M. Yano: Strength Evaluation of Spheroidal Graphite Cast Iron, (AGNE Gijutsu Center, Tokyo, 1999) pp. 60-63.
2) B. Zhao, S. Suzuki and H. Nakae: Materia Japan 52 (2013) 3-9.

3) H. Nakae and Y. Igarashi: J. JFS 74 (2002) 197-204.

4) H. Nakae: Engineering Casting, (Sangyo Tosyo, Tokyo, 2008) pp. 178-180.

5) H. Nakae, H. Shin, M. Hara and Y. Harada: J. JFS 75 (2003) 337-343.

6) V.H. Patterson: Foundry Trade J. 26 (1973) 91.

7) H. Nakae, H. Kiyosuke and S. Okada: J. JFS 51 (1979) 684-690.

8) Japan Foundry Association: The Handbook on Casting, (Maruzen, Tokyo, 1986) pp. 565-566.

9) H. Horie: Casting Forging and Heat Treatment 393 (1980) 9-22.

10) H. Horie: J. JFS 49 (1977) 393-399.

11) F. Lietaet, P. Hilaire and C. Staroz: AFS International Cast Metals Journal (March) (1982) 30-43.

12) H. Takeda, H. Yoneda and K. Asano: Mater. Trans. 51 (2010) 176185.

13) H. Horie and T. Kowata: J. JFS 60 (1988) 173-178.

14) T. Kowata, H. Horie, M. Nakamura, S. Hiratsuka and A. Chida: J. JFS 65 (1993) 209-214.

15) Y. Igarashi and S. Okada: J. JFS 70 (1998) 329-335.

16) H. Nakae, Y. Igarashi and Y. Ono: J. JFS 73 (2001) 111-117.

17) H. Nakae, H. Fujii, B. Zhao and T. Shinohara: J. JFS 75 (2003) 545551.

18) H. Nakae: Report of the 171st JFS Meeting (J. JFS, 2018) p. 1. 